\title{
1 The impact of the Three Gorges Dam on summer streamflow in the
}

3 Running title: Impact of Three Gorges Dam on summer streamflow

4 Zhenkuan $\mathrm{Su}^{1}$, Michelle $\mathrm{Ho}^{2,3}$, Zhenchun Hao ${ }^{1,4}$, Upmanu Lall ${ }^{2,5}$, Xun Sun ${ }^{2,6}$, Xi Chen ${ }^{7}$,

$5 \quad$ Longzeng $\mathrm{Yan}^{8}$

$6{ }^{1}$ State Key Laboratory of Hydrology-Water Resources and Hydraulic Engineering, Hohai

7 University, Nanjing 210098, China

$8 \quad{ }^{2}$ Columbia Water Center, Columbia University, New York, NY 10027, USA

$9 \quad{ }^{3}$ CSIRO Land and Water, Canberra, ACT, 2601, Australia

$10{ }^{4}$ National Cooperative Innovation Center for Water Safety \& Hydro-Science, Hohai University,

11 Nanjing 210098, China

$12{ }^{5}$ Department of Earth and Environmental Engineering, Columbia University, New York, NY 10027,

13 USA

$14{ }^{6}$ Key Laboratory of Geographic Information Science (Ministry of Education), East China Normal

15 University, Shanghai 200241, China

$16{ }^{7}$ Bureau of Hydrology, Changjiang Water Resources Commission, Wuhan 430010, China

$17{ }^{8}$ Upper Changjiang River Bureau of Hydrology and Water Resources Survey, Bureau of Hydrology,

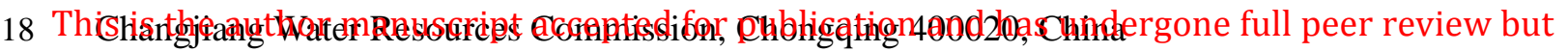
has not been through the copyediting, typesetting, pagination and proofreading process, which

19 maxdRabwledifferkents between this version and the Version of Record. Please cite this article as doi: 10.1002/hyp.13619 
20 We would like to sincerely thank our colleagues at Hohai University and the Columbia Water

21 Center, Columbia University for their constructive feedback and critique. This work was supported

22 by the National Key Research Projects (Grant No.2018YFC1508001 and No.2016YFC0402704).

\section{Correspondence}

24 Zhenchun Hao, State Key Laboratory of Hydrology-Water Resources and Hydraulic Engineering,

25 Hohai University, Nanjing 210098, China. E-mail: hzchun-hhu@163.com

26 


\section{The impact of the Three Gorges Dam on summer streamflow in the Yangtze River Basin}

\section{Abstract}

The Three Gorges Dam is the world's largest capacity hydropower station located in the Hubei province along the Yangtze River in China, which began operations in 2003. The dam also functions to store and regulate the downstream releases of water in order to provide flood control and navigational support in addition to hydropower generation. Flow regulation is particularly important for alleviating the impacts of low and high flow events during the summer rainy season (June, July, and August). The impact of dam operations on summer flows is the focus of this work. Naturalized flows are modelled using a canonical correlation analysis and covariates of subbasin-scale precipitation resulting in good model skill with an average correlation of 0.92 . The model is then used to estimate natural flows in the period after dam operation. A comparison between modelled and gauged streamflow post 2003 is made and the impact of the dam on downstream flow is assessed. Streamflow variability is found to be strongly related to rainfall variability. An analysis of regional streamflow variability across the Yangtze River Basin showed a mode of spatially negatively correlated variability between the upper and lower basin areas. The Three Gorges Dam likely mitigated the occurrence of high flow events at Yichang station located near the dam. However, the high flow at the remaining stations in the lower reach is not noticeably alleviated due to the diminishing influence of the dam on distant downstream flows and the impact of the lakes 
46

47

48

49

\section{1. Introduction}

51

52

53

54

55

56

57

58

59

60

61

62

63

64

downstream of the dam that act to attenuate flows. Three types of flow regime changes between naturalized and observed flows were defined and used to assess the changes in the occurrence of high and low flow events resulting from dam operations.

Keywords: Three Gorges Dam; Canonical correlation analysis; High flow; Low flow

The Yangtze River Basin in China is home to one-third of the country's population and the largest capacity hydropower project in the world to date - the Three Gorges Dam (TGD) (Figure 1). The river is also known as "Changjiang" in China - its literal translation being "long river", which reflects its status as the longest river in Asia and is a significant region in terms of China's history, culture, and economy (Bermudez, 2015).

The basin's climate is characterized by complex regional subbasin-scale patterns of precipitation and temperature in terrain ranging from plateaus to plains. The combination of complexity in both climate and terrain results in widely varying rainfall-runoff processes across the basin that spans an area of 1.8 million $\mathrm{km}^{2}$. Periodic floods and droughts have been experienced in the basin throughout history and a number of extreme events have captured the public's attention due to the loss of life and impacts on the regional economy (Bing et al., 2012; Wang et al., 2011; Xu et al., 2008; Yin et al., 2001). For example, in 1998 floods destroyed 4970000 houses (Zong et al., 2000) while a drought in 1994 was estimated to have resulted in economic losses of CNY 20 billion (approximately $\$ 2.3$ billion USD) (Zhang et al., 2015). 
The TGD was originally conceived almost a century ago but progress was interrupted by political and social upheavals. Construction of the TGD began in 1993 with flow regulation and water impoundment commencing in 2003. Chinese laws and regulations stipulate that the primary function of any water conservancy project must be flood storage and control. That is, flood control operations will take precedence over other functions such as hydropower, transport and water security. The dam is therefore operated to reduce the impacts of floods in spring and summer, while water is released over winter and autumn to maintain downstream flows for water supply and to facilitate navigation (Zhao et al., 2012). The Yangtze River has experienced a number of severe low flow events (e.g. in 2006, 2008, 2011) resulting in suspension of navigation in reaches downstream of the TGD, loss of residential water supply for hundreds of thousands in the Hubei Province (Qiu, 2011), and water shortages that impacted 18 million people during the 2006 autumn drought over the Sichuan and Chongqing provinces (Zhang et al., 2015). Such events have raised concerns regarding the effectiveness of the dam in providing seasonal flow regulation. Past studies have focused on the TGD's impacts on downstream lakes, river levels and flows (Chen et al., 2016; Jiang et al., 2014; Lai et al., 2014; Li et al., 2016; Mei et al., 2015; Wang et al., 2017; Wang et al., 2013), however, the changes in flow regimes between naturalized flows and observed flows impacted by the dam and the underlying mechanism have been largely overlooked. Consequently, an analysis that compares estimated naturalized flows against flows regulated by the TGD in the period post impoundment is important for determining whether dam operations likely reduced or exacerbated 
low flow or high flow occurrences, and how the occurrence of these flow types have changed.

Numerous approaches for estimating naturalized flows have been used including distributed hydrological models and stochastic models. Hydrological models such as the physically based Soil and Water Assessment Tool (SWAT) model, MIKE SHE, and Variable Infiltration Capacity (VIC) model have been widely used in the analyses of streamflow modelling and their predictions (Kim et al., 2016; Liang et al., 1994; Vansteenkiste et al., 2013; Yuan et al., 2004). However, distributed hydrological models are limited by large data requirements, unclear parameter uncertainty, and inaccurate modelling of physical process (Gayathri et al., 2015; Pechlivanidis et al., 2011). Data constraints, such as limited data on catchment characteristics and land use limit the ability to accurately model hydrological processes using physically based models.

4

Alternatively, statistically-based models, such as regression and correlation models, are observation-oriented methods that seek to find functional relationships between explanatory and response variables (Elsanabary et al., 2015; Kwon et al., 2009; Steinschneider et al., 2016). These models are data orientated and do not explicitly consider the process driving the hydrological system. In addition, stochastic models are typically comprised of a relatively small number of model parameters. These models therefore allow for a parsimonious characterization of streamflow variability. Yangtze River Basin streamflow has been shown to be strongly related to rainfall particularly at coarser (seasonal to annual) timescales. For example, the correlation coefficient between annual precipitation and streamflow at Datong station in the Lower Yangtze River Basin is 
103

104 region.

105 Here, we assess the impacts of the TGD on summer flows using a statistical approach to model

106 naturalized flows and comparing these modelled flows with observed flows in the period following

107 dam operation. The rainfall and streamflow data used in the analysis are described in Section 2

108 along with key hydrological features along the Yangtze River. The canonical correlation analysis

109 used to model streamflow across the basin is described in Section 3 and we address the issue of high

110 spatial correlation among both rainfall covariates and streamflow. In Section 4 we quantify the

111 relationship between summer (the wettest season) rainfall and streamflow along the main stem of

112 the Yangtze River downstream of the TGD. The spatial and temporal patterns of rainfall anomalies

113 over the whole basin are used to qualitatively assess whether changes in rainfall variability can

114 likely explain changes in streamflow in the post dam period compared with modelled streamflow.

115 We also assess the influence of the dam on summer flow by identifying changes in low, normal and

116 high flow regimes. We find that the TGD likely attenuates both high and low flows at downstream

117 locations close to the dam. However, the dam's impacts are largely eliminated on flows further

118 downstream.

119

120

121

\section{Study area and data description}

The TGD is located approximately $1880 \mathrm{~km}$ upstream of the estuary where the Yangtze River flows into the East China Sea, and significant landmarks of the Dongting Lake (covering an area of 
$\left.1222625 \mathrm{~km}^{2}\right)$ and Poyang Lake $\left(\sim 4125 \mathrm{~km}^{2}\right)$ are located in this reach. To assess the likely impacts of

123 dam operations on regulating summer high and low flows along the Yangtze River, we use

124 streamflow data from four hydrological stations downstream of the dam located on the main stem at

125 Yichang, Luoshan, Hankou, and Datong (Figure 1).

126 The Yichang station is known as the "Gateway to the Three Gorges" and is located approximately

$12740 \mathrm{~km}$ downstream of the dam. The Luoshan station is located close to the outlet of the Dongting

128 Lake that aggregates the flows from two major subbasins (i.e. Yuanshui and Xiangjiang). As a result,

129 streamflow at Luoshan station is impacted by natural water detention in the lake. Hankou station

130 was selected due to its importance for flood monitoring given its location downstream of where the

131 Han River, which is the largest tributary, joins the main stem of the Yangtze River. Similar to the

132 Luoshan station, streamflows at Datong station are impacted by lake effects due to its location

133 downstream of Poyang Lake. The station is also critical for monitoring environmental flows and

134 outflows to the sea.

135 Daily streamflow records were obtained from the Changjiang Water Resources Commission. Data

136 have been checked and quality controlled and cover the period from 1960 to 2014 for each of the

137 four stations. The monthly averaged streamflow data was obtained by averaging the daily flow rates

138 within each month. The annual hydrograph shows the seasonality of streamflow (Figure 2), which is

139 monsoon summer (June-July-August) flow dominated. As a result, the summer season (JJA) was

140 selected to enable an analysis of changes in the occurrence of high and low flows. The summer 
141 streamflow was logarithmically transformed as the streamflow at all four stations were

142 approximately log-normally distributed.

143 Daily rainfall data was accessed from the China Meteorological Data Service Center (2016).

144 Rainfall records that span from 1960 to 2014 with less than 5\% missing values were selected

145 resulting in data from 136 weather stations. For each station, missing values were infilled using the

146 average values from the two nearest stations with rainfall recorded on that day. The intra-annual

147 pattern of rainfall is similar to that of streamflow with maximum monthly precipitation occurring

148 during summer. The gauged rainfall data was spatially aggregated using the 21 subbasin boundaries

149 (Figure 1) obtained from the Changjiang Water Resources Commission. The rainfall over a given

150 subbasin is the spatially averaged value across all rainfall stations within the subbasin using the

151 Thiessen Polygon Method (Zhong et al., 2018). The spatial distribution of rainfall stations is highly

152 heterogeneous. The Thiessen polygon method was applied as this approach accounts for the uneven

153 distribution of rainfall sites, allowing for a more reasonable representation of aggregated rainfall.

154 This method assigns an area called the Thiessen polygon (or the Voronoi diagram) to each rainfall

155 station thereby providing an area-weighted average, which was applied to all stations within a

156 subbasin to attain the aggregate subbasin rainfall.

\section{3. Methodology}

158 Here we present an approach for modelling unregulated summer streamflow using rainfall as a

159 covariate. Canonical correlation analysis was selected to model the relationship between rainfall 
and streamflow to account for rainfall induced changes of the streamflow across the four

161 hydrological stations. The model performance metrics and method of analysis of the dam impact on

162 summer streamflow were then described. The conveyance period for streamflow to travel from the

163 upper catchment to the estuary is approximately 14 days (Chu et al., 2006), which is less than our 3

164 month time scale. Given the relatively coarse temporal resolution considered, we did not consider a

165 temporal lag in our analysis.

\section{$166 \quad 3.1$ Model design}

167 The date of June 2003, hereon used to define the pre- and post-dam periods, delineates the change

168 from a free-flowing river to an impounded river as this was the time at which storage in the

169 reservoir behind the TGD began to accumulate. Initial diagnostic analyses were conducted using the

170 rank correlation analysis between the rainfall $x_{t, k}$ in year $t$ at subbasin $k$, and the $\log$ transformed

171 streamflow $\ln \left(y_{t, s}\right)$ in year $t$ at station $s$ in the pre-dam period (shown in Figure 3). The summer

172 flow data for all stations have the strongest positive correlations with spatially averaged rainfall

173 over adjacent subbasins. However, rainfall over some subbasins far away from the streamflow

174 stations has a negative correlation with the flow (e.g. the correlation of flow at Luoshan and rainfall

175 over Mintuojiang in upper basin).

176 Physically, rainfall can only contribute to downstream streamflow, however, rainfall in a

177 downstream subbasin may be indicative of regional climate that influences streamflow across the

178 basin (e.g. the precipitation over a downstream catchment may be negatively correlated with 

each subbasin.

181 The spatial and temporal relationship between rainfall and streamflow can be expressed by a

182 formula $y=f(x)$, where $y$ is streamflow and $x$ is rainfall. The model was fit using data prior to 1832003 in order to quantify the rainfall-runoff relationship prior to regulations by the TGD. The model 184 was then used to estimate the streamflows post 2003 as informed by rainfall. The estimated flows 185 are referred to as modelled naturalized flows here and are compared with the gauged flows post 1862003 to assess the likely impacts of streamflow regulation by the TGD. A canonical correlation 187 analysis (CCA) was applied to maximize the correlation between the covariates and the target 188 variables.

\subsection{Canonical correlation analysis}

190

The proximity of the 21 subbasins results in covariates that are significantly correlated. Preliminary analysis (not presented here) showed that the correlations between many subbasins were greater than 0.9. Regression models require the explanatory variables to be significantly independent in order to avoid multicollinearity. Thus, canonical correlation analysis (CCA) (Hotelling, 1936) was

194 implemented to allow for dimension reduction among the highly correlated rainfall data. CCA 195 differs from other methods of dimension reduction such as principle component analysis (PCA) 196 (Jolliffe, 2002) and archetype analysis (AA) (Cutler et al., 1994; Steinschneider et al., 2015; Stone 197 et al., 1996) as CCA is constructed to maximize the correlation between the explanatory and target 
198

199

variable through a linear transform. It has been used in applications of reconstructing streamflow using paleoclimate records (Ho et al., 2016), refining climate projections (Chen et al., 2017) and assessing regional flood frequency (Ouarda et al., 2001).

A brief description of CCA is presented here and we refer readers to Hotelling (1936) for more details. CCA consists of the linear transform of two variables to canonical form in order to maximize the correlation between them. Given two random variables $X$ and $Y$, where $X$ and $Y$ consist of $p$ and $q$ variables respectively, there exist two vectors $a$ (of length $p$ ) and $b$ (of length $q$ ) such that $U=a^{\prime} X$ and $V=b^{\prime} Y$ where the correlation between $U$ and $V$ is maximized. $U$ and $V$ yield the first pair of canonical variables. Subsequent canonical pairs may be derived but with the additional constraint that they are orthogonal to previously identified canonical variables. Dimension reduction is achieved by selecting fewer than $\min (p, q)$ pairs of canonical variables. In this study, the explanatory variable $X$ is comprised of rainfall $x_{t, k}$ for $k \in 1: 21$ subbasins and the target variable $Y$ is the $\log$-transformed streamflow $\ln \left(y_{t, s}\right)$ for $s \in 1: 4$ and $t \in 1960: 2014$ for both $X$ and $Y$. In our study, the algorithm of CCA is implemented using the CCA package in $\mathrm{R}$ language by Gonzalez et al. (2008).

The first 4 pairs of canonical variables were retained to develop models relating rainfall and streamflow. For each pair, a linear regression equation was built using Equation (1).

$V_{i}=\beta_{i} U_{i}+\alpha_{i}+\varepsilon_{i}$

where, $i$ is a value ranging from 1 to 4 , denoting the order of the 4 pairs of canonical variables. $\beta_{i}$ 
217 is the regression coefficient and $\alpha_{i}$ is the intercept in $i$-th linear equation. $\varepsilon_{i}$ is the error term and

218 involves various uncertainties stemming from variability in streamflow unaccounted for by rainfall.

219 Rainfall in the post dam period is used as covariates to estimate the naturalized streamflow using

220 the canonical covariates $a$ and Equation (1). Log-transformed streamflow is obtained by calculating

$221 \quad V$ and back transforming $V$ using canonical weights $b$. Streamflows were then back transformed

222 from the log space.

\section{$223 \quad 3.3$ Model performance metrics}

224 A leave-m-out cross validation method was applied to verify the skill of the model. In this process,

$225 m$ randomly selected observations of streamflow data are retained for validation, while the

226 remaining $n-m$ data are used for model calibration, where $n$ is the total number of observations. In

227 this study, we first used $m=5$ (approximately $10 \%$ of the total number of observations) and

228 randomly selected $m$ data points without replacement from the time series. The remaining 38 years

229 of data were used for model calibration. The procedure was repeated 100 times to produce a set of

230 validation metrics computed from all the cross validated models. Two metrics, the reduction of error

231 (RE) and the coefficient of efficiency (CE) (Cook et al., 1994; Wilson et al., 2010) for those original

232 variables rather than the canonical variables, were chosen to verify the performance and

233 predictability of the model. These are defined as follows in Eq. (2) and Eq. (3):

$234 \quad \mathrm{RE}=1-\frac{\sum\left(x_{i}-\hat{x}_{i}\right)^{2}}{\sum\left(x_{i}-\bar{x}_{c}\right)^{2}}$

$235 \mathrm{CE}=1-\frac{\sum\left(x_{i}-\hat{x}_{i}\right)^{2}}{\sum\left(x_{i}-\bar{x}_{v}\right)^{2}}$ 
236 Where, $x_{i}$ and $\hat{x}_{i}$ are the observed and predicted streamflow in year $i$ of the validation period,

237 respectively. $\bar{x}_{c}$ is the mean of observations used for calibration and $\bar{x}_{v}$ is the mean of

238 observations used for validation. Theoretically, the values of both RE and CE range from the

239 negative infinity to a maximum of 1 , with higher values indicating better prediction skill. A positive

240 value indicates that the model has better predictive skill than using the climatology of the

241 verification period. The RE and CE statistics are similar to the Nash-Sutcliffe efficiency score

242 (McCuen et al., 2006; Nash et al., 1970) and have previously been used to assess the performance

243 of streamflow models (Chen et al., 2014; Devineni et al., 2013; Ho et al., 2016).

\section{$244 \quad 3.4$ Analysis of the impact of the TGD on summer streamflow}

245 Based on the modelled streamflow across the four hydrological stations, 5-year moving averages of

246 the modelled naturalized streamflow at each gauge were calculated. The observed and modelled

247 streamflows are first qualitatively assessed. To analyze the variability of the non-regulated flow in

248 both space and time principal component analysis (PCA) was applied.

249 Changes in streamflow during the post-dam period are induced by both rainfall variations and dam

250 regulation. We therefore analyze and interpret variations in streamflow in the post dam period by

251 considering the probable impacts of both variable rainfall and dam regulation. A qualitatively

252 assessment of the influence of rainfall variability on summer flow was first investigated to show

253 whether the changes in flow were possibly due to changes in rainfall. Then changes in flows at the

254 four streamflow locations due to dam regulations were quantitatively assessed using estimates of 
naturalized flows informed by rainfalls.

256 To quantitatively assess the differences between the modelled and observed streamflow during the

257 post-dam period the frequency of high flow and low flow events and quantiles of summer flow were

258 calculated for modelled and observed streamflow pre and post 2003. The comparison between

259 streamflow before and after dam operation provides an approach to assessing the impact of the dam

260 on either exacerbating or mitigating extreme events. We define a high flow occurrence as a

261 streamflow event greater than the $75^{\text {th }}$ percentile summer flow of the pre-dam period. Similarly, a

262 low flow occurrence is streamflow less than the $25^{\text {th }}$ percentile summer flow of the pre-dam period.

\section{4. Results}

\section{$264 \quad 4.1$ Model results}

265 The summer streamflows for all gauges along the main stem were modelled using the spatially

266 averaged rainfall data and resulted in mean adjusted $R^{2}$ value of 0.80 . The mean modelled

267 streamflows along with the $5^{\text {th }}-95^{\text {th }}$ prediction interval are shown in Figure 4 . The modelled

268 streamflows closely match the observations, and the average correlation across all stations was 0.92.

269 Some rainfall-runoff models have shown improved results when spatially averaged rainfall is used,

270 compared with using gauged data (Tramblay et al., 2011).

271 To verify the performance and predictive skill of the model, cross validation was performed. The

$272 \mathrm{RE}$ and $\mathrm{CE}$ values were calculated, and the results are presented in boxplots (Figure 5). There 
resulted in a model with median RE and CE values of around 0.8 for all streamflow sites, indicating

274 that the associated model predictions are more informative than climatology of the verification

275 period.

\section{$276 \quad 4.2$ Main modes of natural streamflow variability}

277 Summer averaged streamflows at the four selected gauges within the Yangtze River Basin modelled

278 using subbasin-scale rainfall were used to further analyze changes in streamflow response pre and

279 post dam regulation. Both modelled and observed summer streamflow for the period 1960-2014 are

280 shown in log space in Figure 6.

281 Prior to dam regulation the temporal variability of modelled streamflows closely matches that of the

282 observations for all stations. The low flows in the early 1970s and high flows in the late 1990s

283 (Gemmer et al., 2008) are visible in both the observed and modelled flows at all stations. The 5-year

284 moving averages show the flows for the four stations fluctuate periodically. In the early 1970s all

285 stations experienced negative summer flow anomalies. Negative streamflow anomalies are also

286 observed and modelled in three of the stations (i.e. Luoshan, Hankou and Datong) in the late 1980s.

287 In contrast, the early 1980s showed a persistent flood regime with positive anomalies seen in the

$288 \quad 5$-year moving averages for all stations.

289 PCA was used to extract the main spatiotemporal modes of logarithmically transformed modelled

290 streamflows across all four stations to investigate their relationships both in space and time. A scree

291 test was used to inform the number of PCs to retain (scree plot was shown in Figure S1 of the 
supporting information). The first two PCs were retained and together explain over $97 \%$ of the streamflow variance (PCs were shown in Figure 7).

294 For PC1, the loading values are of the same sign across all stations representing a regionally 295 cohesive signal. Both the flood in 1998 and drought in 1972 (Heng et al., 1999; Jiang et al., 2017;

296 Yang et al., 1982; Zhang et al., 2015) are evident in the PC scores. During the 1998 floods, water transport from three regions, the Indian Ocean, the Bay of Bengal-South China Sea, and the Pacific Ocean, resulted in persistent heavy rainfall over the southwestern, southern and southeastern 299 subbasins, respectively, culminating in a widespread severe flood (Jiang et al., 2017). Conversely, a 300 large negative score for PC1 can be seen in 1978, when the middle and downstream Yangtze River 301 Basin were struck by a severe drought event resulting from reduced summer precipitation (Zhang et 302 al., 2015).

303 Unlike PC1, PC2 represents a non-homogeneous pattern of streamflow variability in the Yangtze 304 River Basin (see loading values for PC2 in Figure 7). The loading values are of opposite sign for 305 Yichang station close to the dam versus those located further downstream. This mode of variability 306 distinguishes between streamflow in the mid to upper basin and the lower basin and is 307 representative of the differences in regional climate and streamflow response. For example, Figure 6 308 shows anomalously low flows at Yichang station in 1969, however the remaining three downstream 309 stations experience average to above average flows. A similar signal is seen in 1996 where flow at 310 Yichang is average or slightly above average, while streamflows at the remaining three stations are 
311 anomalously high. This signal is reversed in 1981 when flow at Yichang is above average and flows

312 at the downstream stations show negative anomalies.

\section{$313 \quad 4.3$ Influence of rainfall variability on summer streamflow}

314 High correlations between streamflow and precipitation suggest that streamflow variability is

315 strongly influenced by precipitation variability. The spatial and temporal patterns of rainfall

316 anomalies over the whole basin (Figure S2 of supporting information) are therefore first used to

317 qualitatively assess whether changes in rainfall variability can likely explain changes in streamflow

318 in the post dam period.

319 In the years of 2003 and 2010, anomalously high rainfalls were experienced in the subbasins located

320 the northern section of upstream of Yichang station (e.g., Jialingjiang basin), which should have

321 resulted in a high flow event. However, the dam operation likely reduced the magnitude of the flow

322 as evident by the reduced streamflow observations compared to the modelled flows at Yichang

323 station, which was likely due to decreased water releases thereby retaining the floodwaters and

324 reducing the downstream flows. Streamflow at the remaining three gauges further downstream were

325 not notably impacted by dam operations.

326 In 2008, streamflow observations at all four gauges recorded below average flows despite rainfall in

327 the northern section of the lower basin being slightly above average. It is likely that decreased

328 outflows from the dam in combination with decreased rainfall in the lower basin region resulted in

329 low flow conditions at Hankou and Datong stations downstream of the Dongting Lake. 
In 2012, average rainfall was observed over the central region of the Yangtze River Basin with the exception of the Qingjiang subbasin, a relatively small subbasin located in the center of the basin (Figure 1). No notable change was observed at Yichang station when comparing modelled and observed streamflows. However, water supply from the lakes downstream (e.g. Dongting Lake and Poyang Lake), where above average rainfalls were observed, may have contributed to increased flows at Luoshan, Hankou and Datong stations compared with naturalized flows.

\subsection{Dam impacts on summer streamflow}

The modelled streamflows represent naturalized flows unimpacted by dam regulation and were compared with the observed flows for all stations in the post dam period to assess potential changes in the occurrence of high and low flows. The difference between the modelled and the gauged values therefore represents the difference in streamflow as a result of dam operations in addition to model errors. Figure 8 shows the distribution of high flow and low flow events for the non-regulated flows from 1960 to 2014 with results for the period of 2003-2014 obtained using modelled flows. Figure 8 shows that low flows and high flows may be wide spread across the basin (e.g. basin-wide high flows occurred in 1962, and basin-wide low flows occurred in 1971). These high and low flow also can co-occur in different regions of the basin (e.g. 1981 with low flow conditions in the lower basin and high flow conditions in the middle basin). Streamflows across the basin are neutral (i.e. in middle two quartiles) in approximately $16 \%$ of years.

The frequency of high flow and low flow events in the pre and post dam periods is shown in Table 1 
349 for both modelled naturalized and observed flows. The frequency of high flow events for Yichang

350 increased by 0.12 when comparing naturalized flows. The remaining stations show a decreased

351 frequency in high flow events with a decrease in high flow frequency of 0.09 for Luoshan and

352 Hankou and 0.03 for Datong. The frequency of low flow events for all stations increased by

353 0.04 0.12. Compared with the modelled naturalized flows, the frequency of high flow events at

354 Yichang and Datong are reduced in the post-dam period, which indicates that the operation of the

355 dam has likely contributed to the greatly reduced occurrence of high flow events. While the TGD

356 appears to have attenuated the magnitude of high flow events, the occurrence of low flow events

357 appear to have been magnified as seen when comparing modelled and observed low flow

358 occurrences in the period post 2003.

359 The observed and modelled flows in the post dam period (2003-2014) are plotted as quantiles of the

360 flows in the pre-dam period in Figure 9. The threshold lines of high flow and low flow events were

361 plotted in Figure 9 shown by dashed and solid line respectively. These threshold values are used to

362 identify three types of changes in occurrence of high flows or low flows at the four stations

363 resulting from dam operation. The first type of flow regime change is defined as a year in which a

364 high flow or low flow is identified in the naturalized flows, but has been alleviated by dam

365 operations as evident in the observed flows. The second case is when no high flow or low flow is

366 evident in the naturalized flows, but occurs in the observed record. The third case is when a high

367 flow or low flow is observed in the naturalized flows, but the observed flows show the opposite 

of flow regime changes occur are tabulated in Table 2.

370 From Table 2 and Figure 9, it can be seen that in the 12 years between 2003 and 2014 that the dam 371 likely mitigated high flow events at Yichang in three of these years (i.e. 2003, 2010, 2014) and at Luoshan in 2014 exemplifying the first type of flow regime change. In contrast, these high flow events were not alleviated by dam operations for the lower reach. These middle and lower basin regions are influenced by lake effects upstream of the stations (Wang et al., 2017) and consequently dam operations have limited noticeable impacts further downstream. An example of the second case of flow regime change occurred in 2012, where either a high or low flow event is observed, but does not appear in the modelled naturalized flows. Here, the naturalized flows are within the $25^{\text {th }}-75^{\text {th }}$ percentile range at Luoshan, Hankou and Datong. However, the observed high flows 379 indicate that the combination of dam operations and lake effects resulted in increased flows at these 380 locations. Similarly, in 2013, a low flow event for Luoshan and Hankou was observed, while was 381 not evident in the modelled naturalized flows. A similar occurrence is seen in 2008 at Yichang and 382 Luoshan. In the same year of 2008, the third type of flow regime change occurred in the two 383 stations further downstream of the dam. That is, the naturalized flow for Hankou and Datong show 384 a high flow event while the observation indicates the occurrence of a low flow event. The flow for Datong in 2013 shows a similar change in events. 
flow occurrence in the middle and lower portions of the basin. These reasons include: 1) The topography of the lower basin is dominated by relatively flat plains containing large areas of lakes

389 (a total lake area of $15000 \mathrm{~km}^{2}$ ). These lakes naturally attenuate the tributary flows, which impact

390 flows to the main stem. These lake effects on streamflow occur in addition to the impacts imposed

391 by the TGD (Wang et al., 2017). 2) The Yangtze River Basin consists of 21 subbasins (see Figure 1),

392 whose runoff form the main components of inflows at the four downstream hydrological stations.

393 However, spatial heterogeneity in rainfall and catchment responses mean that high flow and low

394 flow events do not necessarily co-occur across the different sub-basins. Perhaps more importantly,

395 the geographical distribution of the precipitation in the Yangtze basin generally increases from

396 northwest to southeast. The dam's locations in the drier part of the upper catchment limits the ability

397 to attenuate floods resulting from storm events in the wetter eastern catchments downstream of the

398 dam.

\section{5. Discussion and conclusions}

400 A novel analysis of the impact of the Three Gorges Dam on the summer streamflow in the Yangtze

401 River Basin was presented using canonical correlation analysis to quantify the relationship between

402 the summer streamflow and rainfall across the Yangtze River Basin. The development of the CCA

403 model was motivated by the need to investigate the potential impact of the TGD on summer

404 streamflows by modelling naturalized streamflow and comparing these modelled flows with

405 observed streamflows that are potentially influenced by dam operations. 
406 Another model using rainfalls over each station as covariates was trialed, but the results were not

407 presented in this paper and was hindered by the collinearity and the high dimension of the data.

408 While using a weighted average of the rainfall results in a reduction in variance, this reduction is

409 akin to the natural spatial aggregation represented in the streamflow. The smaller number of

410 sub-basins results in the improved ability to resolve relationships between rainfall and streamflow

411 using CCA compared with using a large number of rainfall stations.

412 The complexity of the model was constrained by the dearth of readily available data that would

413 have improved the streamflow model such as data on catchment characteristics. The approach of

414 CCA addressed the issues of high dimensionality and large spatial correlations of rainfall records

415 over the whole basin.

416 Our study was focused on changes in occurrence of high flow and low flow events as informed by

417 streamflow before and after the commencement of operations of the TGD in 2003 and evaluating

418 the impact of dam operations on mitigating the magnitude of these events. The modelled naturalized

419 streamflows generally closely match the observed streamflows for the four stations. Our analysis

420 shows that the streamflows at Yichang station, located at a relative close proximity to the dam, are

421 more noticeably impacted by the TGD as evident by the reduced occurrence of high flow events

422 after 2003. Flows at the other three stations appear to be less impacted by the dam operations due to

423 the increased distance from the dam, the impacts of the lakes located downstream of the dam (Gao

424 et al., 2013; Guo et al., 2012; Lai et al., 2014) and the inability to attenuate flows generated by 
425

426

427

428

429

430

431

432

433

434

435

436

437

438 439 basin.

440 Several limitations could be addressed in future analyses. First, the model was developed using only

441 summer rainfall excluding other factors, such as the land use change and changes in large scale
442 atmospheric circulation (Xu et al., 2007; Xu et al., 2017). Theoretically, our analysis may result in a
443 conservative estimate of the streamflow but it provides an original approach to assess the likely

441 summer rainfall excluding other factors, such as the land use change and changes in large scale
442 atmospheric circulation (Xu et al., 2007; Xu et al., 2017). Theoretically, our analysis may result in a
443 conservative estimate of the streamflow but it provides an original approach to assess the likely

441 summer rainfall excluding other factors, such as the land use change and changes in large scale
442 atmospheric circulation (Xu et al., 2007; Xu et al., 2017). Theoretically, our analysis may result in a
443 conservative estimate of the streamflow but it provides an original approach to assess the likely

runoff in the higher precipitation regions of the lower basin.

Three types of flow regime change were identified and summarized for the post dam period. The dam did not consistently mitigate the occurrence of either high or low flow events at the four locations considered. These changes in flow regimes, sometimes resulting in high or low flows, suggest that the dam operations are unable, in isolation, to alleviate high flow or low flow events in the lower basin as other factors likely influence these events at distant locations. Although many previous studies demonstrate that the flow regulation in impounded rivers are solely a result of dams (Nilsson et al., 2005), Dai et al. (2012)'s analysis support our result, where they concluded that the flows from the upstream basin of the TGD can only account for about $50 \%$ of changes in multiyear mean flow over the period 1950-2005 at Datong station, and the discharge from the downstream basin accounted for the remaining difference, where flows were influenced by other factors including the effects of Dongting Lake and Poyang Lake and potentially other changes in water use and management. Further, impacts of the TGD on flow so far downstream would largely be masked by significant inflow to the river from the wetter catchments in the eastern Yangtze River 
444 influence of the TGD on streamflows. Second, the approach of CCA demonstrated here considered

445 both the correlations of the streamflow stations and spatial correlations of rainfall stations over the

446 entire Yangtze Basin. An improved understanding of the complex physical processes that influence

447 precipitation occurrence and runoff characteristics would aid in the understanding of changes in

448 runoff and streamflow in the Yangtze River catchment. Such future endeavors are needed to build

449 on past studies such as Chen et al. (2016) and Lai et al. (2014) that have contributed to this

450 understanding and to further our understanding of the influence of the TGD on streamflow. Third,

451 only seasonal high flow regimes were considered here rather than distinct flood events that likely

452 pose the greatest risk to downstream regions.

453 Data Availability Statement

454 Daily streamflow records were obtained from the Changjiang Water Resources Commission. While

455 this data are not publicly available, they may be requested from the Changjiang Water Resources

456 Commission. Daily rainfall data was accessed from the China Meteorological Data Service Center

457 (http://data.cma.cn/en).

458 Supporting information

459 Figure S1. Scree plot showing the variance of each PC for the modelled naturalized streamflows.

460 Figure S2. The spatial and temporal distributions of rainfall anomalies over subbasins of the

$461 \quad$ Yangtze River Basin.

462 References 
Bermudez, C.: Culture and demography in the Yangtze River Basin, China, https://hubpages.com/education/Culture-and-Demography-in-the-Yangtze-River-Basin, Accessed on: 10 Oct., 2015.

Bing, L. F., Shao, Q. Q., \& Liu, J. Y. (2012). Runoff characteristics in flood and dry seasons based on wavelet analysis in the source regions of the Yangtze and Yellow rivers. Journal of Geographical Sciences, 22(2), 261-272. https://doi.org/10.1109/RSETE.2011.5964374.

Chen, J., Finlayson, B. L., Wei, T., Sun, Q., Webber, M., Li, M., \& Chen, Z. (2016). Changes in monthly flows in the Yangtze River, China - With special reference to the Three Gorges Dam. Journal of Hydrology, 536, 293-301. https://doi.org/10.1016/j.jhydrol.2016.03.008.

Chen, X., Hao, Z., Devineni, N., \& Lall, U. (2014). Climate information based streamflow and rainfall forecasts for Huai River basin using hierarchical Bayesian modeling. Hydrology and Earth System Sciences, 18(4), 1539-1548. https://doi.org/10.5194/hess-18-1539-2014.

Chen, X., You, Q., Sielmann, F., \& Ruan, N. (2017). Climate change scenarios for Tibetan Plateau summer precipitation based on canonical correlation analysis. International Journal of Climatology, 37, 1310-1321. https://doi.org/10.1002/joc.4778.

China Meteorological Data Service Center: CMDC, http://data.cma.cn/en, Accessed on: 1 Mar., 2016.

Chu, Z., Zhai, S., \& Chen, X. (2006). Changjiang River sediment delivering into the sea in response to water storage of Sanxia Rervoir in 2003. Acta Oceanologica Sinica, 25(2), 71-79

Cook, E. R., Briffa, K. R., \& Jones, P. D. (1994). Spatial regression methods in dendroclimatology - a review and comparison of 2 techniques. International Journal of Climatology, 14(4), 379-402. https://doi.org/10.1002/joc.3370140404.

Cutler, A., \& Breiman, L. (1994). Archetypal analysis. Technometrics, 36(4), 338-347. https://doi.org/10.2307/1269949.

Dai, Z. J., Chu, A., Stive, M. J. F., \& Yao, H. Y. (2012). Impact of the Three Gorges Dam overruled by an extreme climate hazard. Natural Hazards Review, 13(4), 310-316

Devineni, N., Lall, U., Pederson, N., \& Cook, E. (2013). A tree-ring-based reconstruction of Delaware River Basin streamflow using hierarchical Bayesian regression. Journal of Climate, 26(12), 4357-4374. https://doi.org/10.1175/Jcli-D-11-00675.1.

Elsanabary, M. H., \& Gan, T. Y. (2015). Weekly streamflow forecasting using a statistical disaggregation model for the Upper Blue Nile Basin, Ethiopia. Journal of Hydrologic Engineering, 20(5), 04014064. https://doi.org/10.1061/(ASCE)HE.1943-5584.0001072.

Gao, B., Yang, D. W., \& Yang, H. B. (2013). Impact of the Three Gorges Dam on flow regime in the middle and lower Yangtze River. Quaternary International, 304, 43-50. https://doi.org/10.1016/j.quaint.2012.11.023.

Gayathri, K. D., Ganasri, B. P., \& Dwarakish, G. S. (2015). A review on hydrological models. Aquatic Procedia, 4, 1007-1007. https://doi.org/10.1016/j.aqpro.2015.02.126.

Gemmer, M., Jiang, T., Su, B., \& Kundzewicz, Z. W. (2008). Seasonal precipitation changes in the wet seaon and their influence on flood/drought hazards in the Yangtze River Basin, China. Quaternary 
International, 186, 12-21. https://doi.org/10.1016/j.quaint.2007.10.001.

Gonzalez, I., Dejean, S., Martin, P. G. P., \& Baccini, A. (2008). CCA: An R package to extend canonical correlation analysis. Journal of Statistical Software, 23(12), 1-14. https://doi.org/10.18637/jss.v023.i12.

Guo, H., Hu, Q., Zhang, Q., \& Feng, S. (2012). Effects of the Three Gorges Dam on Yangtze River flow and river interaction with Poyang Lake, China: 2003-2008. Journal of Hydrology, 416, 19-27. https://doi.org/10.1016/j.jhydrol.2011.11.027.

Heng, L., \& Xu, Z. K. (1999). The 1998 floods of the Yangtze river, China. Nature \& Resources, 35(3), 14-21 Ho, M., Lall, U., \& Cook, E. R. (2016). Can a paleodrought record be used to reconstruct streamflow?: A case study for the Missouri River Basin. Water Resources Research, 52. https://doi.org/10.1002/2015WR018444.

Hotelling, H. (1936). Relations between two sets of variates. Biometrika, 28, 321-377. https://doi.org/10.1093/biomet/28.3-4.321.

Jiang, L., Ban, X., Wang, X., \& Cai, X. (2014). Assessment of hydrologic alterations caused by the Three Gorges Dam in the middle and lower reaches of Yangtze River, China. Water, 6, 1419-1434. https://doi.org/10.3390/w6051419.

Jiang, Z., Pu, J., Yang, H., \& Ren, W. (2017). Diagnostic analysis of water vapor transport process during the catastropical flood period over Yangtze River Basin in 1998. Transactions of Atmospheric Sciences, 40(3), 289-298. https://doi.org/10.13878/j.cnki.dqkxxb.201503250113.

Jolliffe, I. T. (2002). Principle component analysis. 2nd Ed., Springer.

Kim, S., Noh, H., Jung, J., Jun, H., \& Kim, H. S. (2016). Assessment of the impacts of global climate change and regional water projects on streamflow characteristics in the Geum River Basin in Korea. Water, 8(3). https://doi.org/10.3390/w8030091.

Kwon, H. H., Brown, C., Xu, K. Q., \& Lall, U. (2009). Seasonal and annual maximum streamflow forecasting using climate information: Application to the Three Gorges Dam in the Yangtze River basin, China. Hydrological Sciences Journal-Journal Des Sciences Hydrologiques, 54(3), 582-595. https://doi.org/10.1623/hysj.54.3.582.

Lai, X. J., Liang, Q. H., Jiang, J. H., \& Huang, Q. (2014). Impoundment effects of the Three-Gorges-Dam on flow regimes in two China's largest freshwater lakes. Water Resources Management, 28(14), 5111-5124. https://doi.org/10.1007/s11269-014-0797-6.

Li, D. Y., Lai, X. J., Dong, Z. C., \& Luo, X. L. (2016). Effects of the Three Gorges Project on the environment of Poyang Lake. Polish Journal of Environmental Studies, 25(6), 2477-2490

Liang, X., Lettenmaier, D. P., \& Wood, E. (1994). A simple hydrologically based model of land surface water and energy fluxes for general circulation models. Journal of Geophysical Research, 99(D7), 14415-14428. https://doi.org/10.1029/94JD00483.

McCuen, R. H., Knight, Z., \& Cutter, A. G. (2006). Evaluation of the Nash-Sutcliffe efficiency index. Journal of Hydrologic Engineering, 11(6), 597-602. https://doi.org/10.1061/(ASCE)1084-0699(2006)11:6(597). 
Mei, X., Dai, Z., van Gelder, P. H. A. J. M., \& Gao, J. (2015). Linking Three Gorges Dam and downstream hydrological regimes along the Yangtze River, China. Earth and Space Science, 2(4). https://doi.org/10.1002/2014EA000052.

Nash, J. E., \& Sutcliffe, J. V. (1970). River flow forecasting through conceptual models part I - A discussion of principles. Journal of Hydrology, 10(3), 282-290. https://doi.org/10.1016/0022-1694(70)90255-6.

Nilsson, C., Reidy, C. A., Dynesius, M., \& Revenga, C. (2005). Fragmentation and flow regulation of the world's large river systems. Science, 308(5720), 405-408. https://doi.org/10.1126/science.1107887.

Ouarda, T. B. M. J., Girard, C., Cavadias, G. S., \& Bobée, B. (2001). Regional flood frequency estimation with canonical correlation analysis. Journal of Hydrology, 254(1-4), 157-173. https://doi.org/10.1016/S0022-1694(01)00488-7.

Pechlivanidis, I. G., Jackson, B. M., Mcintyre, N. R., \& Wheater, H. S. (2011). Catchment scale hydrological modelling: A review of model types, calibration approaches and uncertainty analysis methods in the context of recent developments in technology and applications. Global Nest Journal, 13(3), 193-214

Qiu, J. (2011). China admits problems with Three Gorges Dam. Nature. https://doi.org/10.1038/news.2011.315.

Steinschneider, S., Ho, M., Cook, E. R., \& Lall, U. (2016). Can PDSI inform extreme precipitation?: An exploration with a 500 year long paleoclimate reconstruction over the US. Water Resources Research, 52(5), 3866-3880. https://doi.org/10.1002/2016WR018712.

Steinschneider, S., \& Lall, U. (2015). Daily precipitation and tropical moisture exports across the eastern United States: An application of archetypal analysis to identify spatiotemporal structure. Journal of Climate, 28(21), 8585-8602. https://doi.org/10.1175/Jcli-D-15-0340.1.

Stone, E., \& Cutler, A. (1996). Introduction to archetypal analysis of spatio-temporal dynamics. Physica D, 96(1-4), 110-131. https://doi.org/10.1016/0167-2789(96)00016-4.

Tramblay, Y., Bouvier, C., Ayral, P. A., \& Marchandise, A. (2011). Impact of rainfall spatial distribution on rainfall-runoff modelling efficiency and initial soil moisture conditions estimation. Natural Hazards and Earth System Sciences, 11(1), 157-170. https://doi.org/10.5194/nhess-11-157-2011.

Vansteenkiste, T., Tavakoli, M., Ntegeka, V., Willems, P., De Smedt, F., \& Batelaan, O. (2013). Climate change impact on river flows and catchment hydrology: a comparison of two spatially distributed models. Hydrological Processes, 27(25), 3649-3662. https://doi.org/10.1002/hyp.9480.

Wang, J., Sheng, Y., \& Wada, Y. (2017). Little impact of the Three Gorges Dam on recent decadal lake decline across China's Yangtze Plain. Water Resources Research, 53(5), 3854-3877. https://doi.org/10.1002/2016WR019817.

Wang, J., Sheng, Y. W., Gleason, C. J., \& Wada, Y. (2013). Downstream Yangtze River levels impacted by Three Gorges Dam. Environmental Research Letters, 8(4). https://doi.org/10.1088/1748-9326/8/4/044012.

Wang, M. J., Zheng, H. B., Xie, X., Fan, D. D., Yang, S. Y., Zhao, Q. H., \& Wang, K. (2011). A 600-year flood history in the Yangtze River drainage: Comparison between a subaqueous delta and historical records. Chinese Science Bulletin, 56(2), 188-195. https://doi.org/10.1007/s11434-010-4212-2. 
Wilson, R., Cook, E., D'Arrigo, R., Riedwyl, N., Evans, M. N., Tudhope, A., \& Allan, R. (2010). Reconstructing ENSO: the influence of method, proxy data, climate forcing and teleconnections. Journal of Quaternary Science, 25(1), 62-78. https://doi.org/10.1002/jqs.1297.

Xu, J. J., Yang, D. W., Yi, Y. H., Lei, Z. D., Chen, J., \& Yang, W. J. (2008). Spatial and temporal variation of runoff in the Yangtze River basin during the past 40 years. Quaternary International, 186, 32-42. https://doi.org/10.1016/j.quaint.2007.10.014.

Xu, K., Brown, C., Kwon, H.-H., Lall, U., Zhang, J., Hayashi, S., \& Chen, Z. D. (2007). Climate teleconnections to Yangtze river seasonal streamflow at the Three Gorges Dam, China. International Journal of Climatology, 27(6), 771-780. https://doi.org/10.1002/joc.1437.

Xu, S., Zhang, Y., Dou, M., Hua, R., \& Zhou, Y. (2017). Spatial distribution of land use change in the Yangtze River Basin and the impact on runoff. Progress in Geography, 36(4), 426-436. https://doi.org/10.18306/dlkxjz.2017.04.004.

Yang, G., \& Liang, P. (1982). The relationship between the flow pattern variation over lower troposphere in low latitudes and the persistent drought and flood in the middle and lower Yangtze valleys. Plateau Meteorology, 1(3), 43-51

Yin, H., \& Li, C. (2001). Human impact on floods and flood disasters on the Yangtze River. Geomorphology, 4l(2), 105-109. https://doi.org/10.1016/S0169-555X(01)00108-8.

Yuan, F., Xie, Z. H., Liu, Q., Yang, H. W., Su, F. G., Liang, X., \& Ren, L. L. (2004). An application of the VIC-3L land surface model and remote sensing data in simulating streamflow for the Hanjiang River basin. Canadian Journal of Remote Sensing, 30(5), 680-690. https://doi.org/10.5589/m04-032.

Zhang, L. X., \& Zhou, T. J. (2015). Drought over East Asia: A review. Journal of Climate, 28(8), 3375-3399. https://doi.org/10.1175/JCLI-D-14-00259.1.

Zhang, Z. X., Chen, X., Xu, C. Y., Yuan, L. F., Yong, B., \& Yan, S. F. (2011). Evaluating the non-stationary relationship between precipitation and streamflow in Nine Major Basins of China during the past 50 years. Journal of Hydrology, 409(1-2), 81-93. https://doi.org/10.1016/j.jhydrol.2011.07.041.

Zhao, J., Li, J., Dai, Z., Wang, Y., \& Zhang, A. (2012). Analysis the runoff variation of Yangtze River in Yichang. Resources Science, 34(12), 2306-2315

Zhong, W., Li, R., Liu, Y. Q., \& Xu, J. (2018). Effect of different areal precipitation estimation methods on the accuracy of a reservoir runoff inflow forecast model. IOP Conference Series: Earth and Environmental Science, 208, 012043. https://doi.org/10.1088/1755-1315/208/1/012043.

Zong, Y. Q., \& Chen, X. Q. (2000). The 1998 flood on the Yangtze, China. Natural Hazards, 22(2), 165-184. https://doi.org/10.1023/A:1008119805106. 
611 Table 1 The frequency of high flow and low flow events pre and post 2003. The modelled

612 frequency for all stations from 2003 to 2014 is only influenced by rainfall, and the observed

613 frequency is influenced by rainfall and TGD.

\begin{tabular}{|c|c|c|c|c|c|c|}
\hline \multirow[b]{2}{*}{ Stations } & \multicolumn{3}{|c|}{ High flow events } & \multicolumn{3}{|c|}{ Low flow events } \\
\hline & $\begin{array}{c}\text { Observed } \\
(1960-2002)\end{array}$ & $\begin{array}{c}\text { Modelled } \\
(2003-201 \\
4)\end{array}$ & $\begin{array}{c}\text { Observed } \\
(2003-201 \\
4)\end{array}$ & $\begin{array}{c}\text { Observed } \\
(1960-2002)\end{array}$ & $\begin{array}{c}\text { Modelled } \\
(2003-2014 \\
)\end{array}$ & $\begin{array}{c}\text { Observed } \\
(2003-20 \\
14)\end{array}$ \\
\hline Yichang & 0.30 & 0.42 & 0.17 & 0.21 & 0.25 & 0.33 \\
\hline Luoshan & 0.26 & 0.17 & 0.17 & 0.21 & 0.33 & 0.42 \\
\hline Hankou & 0.26 & 0.17 & 0.17 & 0.21 & 0.25 & 0.42 \\
\hline Datong & 0.28 & 0.25 & 0.17 & 0.30 & 0.42 & 0.50 \\
\hline $\begin{array}{l}\text { Influence } \\
\text { factors }\end{array}$ & Observations & Rainfall & $\begin{array}{c}\text { Rainfall + } \\
\text { TGD }\end{array}$ & Observations & Rainfall & $\begin{array}{c}\text { Rainfall + } \\
\text { TGD }\end{array}$ \\
\hline
\end{tabular}

614

615 
616 Table 2 The years when the flow regime changed during the post-dam period. Three cases are

617 considered, which include Case 1: "Risk to none" denotes hydrological extremes from occurrence

618 to none; Case 2: "No risk to risk" denotes hydrological extremes from none to occurrence; Case 3:

619 "High/low flow event to low/high flow event" denotes hydrological extremes changed from high

620 flow event to low flow event or from low flow event to high flow event. The signs " $\mathbf{\Delta}$ " and " $\nabla$ "with

621 different colors represent the high flow event and low flow event respectively, red color is Case 1,

622 blue is Case 2, green is Case 3, black means no risk changed.

\begin{tabular}{|c|c|c|c|c|c|c|c|c|}
\hline \multirow{2}{*}{ Year } & \multicolumn{2}{|c|}{ Yichang } & \multicolumn{2}{|c|}{ Luoshan } & \multicolumn{2}{|c|}{ Hankou } & \multicolumn{2}{|c|}{ Datong } \\
\hline & modelled & observed & modelled & observed & modelled & observed & modelled & observed \\
\hline 2003 & $\Delta$ & & & & & & & \\
\hline 2004 & $\nabla$ & $\nabla$ & $\nabla$ & & & & $\nabla$ & $\nabla$ \\
\hline 2005 & $\Delta$ & $\Delta$ & & & & & & \\
\hline 2006 & $\nabla$ & $\nabla$ & $\nabla$ & $\nabla$ & $\nabla$ & $\nabla$ & $\nabla$ & $\nabla$ \\
\hline 2007 & & & & & & & $\nabla$ & \\
\hline 2008 & & $\nabla$ & & $\nabla$ & $\Delta$ & $\nabla$ & $\Delta$ & $\nabla$ \\
\hline 2009 & & & $\nabla$ & $\nabla$ & $\nabla$ & $\nabla$ & $\nabla$ & $\boldsymbol{\nabla}$ \\
\hline 2010 & $\Delta$ & & $\Delta$ & $\Delta$ & $\Delta$ & $\Delta$ & $\Delta$ & $\Delta$ \\
\hline 2011 & $\boldsymbol{\nabla}$ & $\nabla$ & $\nabla$ & $\nabla$ & $\nabla$ & $\nabla$ & $\nabla$ & $\nabla$ \\
\hline 2012 & $\Delta$ & $\Delta$ & & $\Delta$ & & $\Delta$ & & $\Delta$ \\
\hline 2013 & & & & $\nabla$ & & $\nabla$ & $\Delta$ & $\nabla$ \\
\hline 2014 & $\Delta$ & & $\Delta$ & & & & & \\
\hline
\end{tabular}

623

624 
625

626

627

628

629

630

631

632

633

634

635

636

637

638

639

640

641

642

643

Figure 1 The Yangtze River Basin with the main river stem shown in bold and subbasins delineated and annotated with names shown above the figure. The location of the rainfall stations used in the analysis are shown in green. The four hydrological stations that recorded streamflow are shown in red.

Figure 2 Monthly average streamflow (bar plot) for each streamflow station and rainfall amount averaged over the entire Yangtze River Basin.

Figure 3 Rank correlation map between the spatial average rainfall over subbasins in summer (JJA) and the log-transformed average streamflow for each hydrological station in summer (JJA) in pre-dam period.

Figure 4 Model results with $5^{\text {th }}-95^{\text {th }}$ prediction interval for the streamflows over the Yangtze River Basin calibrated using available data (1960-2002) and the canonical variate of subbasin-scale rainfall. The subplots in first row are the result of developed models using four pairs of canonical variables, and second row is the result of observed and modelled streamflow for each hydrological station.

Figure 5 Boxplots of RE (left plot) and CE (right plot) from cross validation with results from the model using sub-basin scale rainfall data.

Figure 6 Model results and observations with 5-yr moving average of the streamflow over Yangtze River Basin. The horizontal dashed line is the average pre-dam period streamflow for each station and the vertical dashed line represents the time before and after the dam starting to retain water (i.e. 
644 Jun. 2003). The blue line with a maker denotes the modelled naturalized streamflow, and the black

645 line with a marker denotes the observed streamflow. The five-year moving averages were also

646 shown with green line and red line representing the modelled naturalized streamflow and observed

647 streamflow, respectively.

648 Figure 7 The first two PCs of summer average streamflows modelled using CCA across the four

649 hydrological stations and their 5-yr moving average over Yangtze River Basin (left), and the

650 corresponding loadings for each station (right). The percentage variance explained is shown in the

651 parenthesis.

652 Figure 8 Distribution of high flow and low flow events for the non-regulated flow from 1960 to

653 2014. Observed streamflows are used in the 1960-2002 period, while naturalized flows modelling

654 using canonical correlation analysis are used in the 2003-2014 period.

655 Figure 9 Comparison of observed and modelled naturalized flows for the four streamflow stations

656 plotted as quantiles of pre-dam flows. The dashed line denotes the $75^{\text {th }}$ percentile (high flows are

657 defined as flows in the top quartile) and the solid line denotes the $25^{\text {th }}$ percentile (low flows are

658 defined as flows in the bottom quartile). 


\begin{tabular}{|lllllll|}
\hline \multicolumn{5}{|c|}{ Name of subbasins } \\
1-JinshajiangUpper & 2-Yalongjiang & 3-JinshajiangLower & 4-Daduhe & 5-Mintuojiang & 6-Chishui & 7-Fujiang \\
8-Qijiang & 9-Jialingjiang & 10-Wujiang & 11-Upper & 12-Qingjiang & 13-Yuanshui & 14-Xiangjiang \\
15-DongtingLake & 16-Hanjiang & 17-Middle & 18-Ganjiang & 19-PoyangLake & 20-Taihu & 21-Lower \\
\hline
\end{tabular}

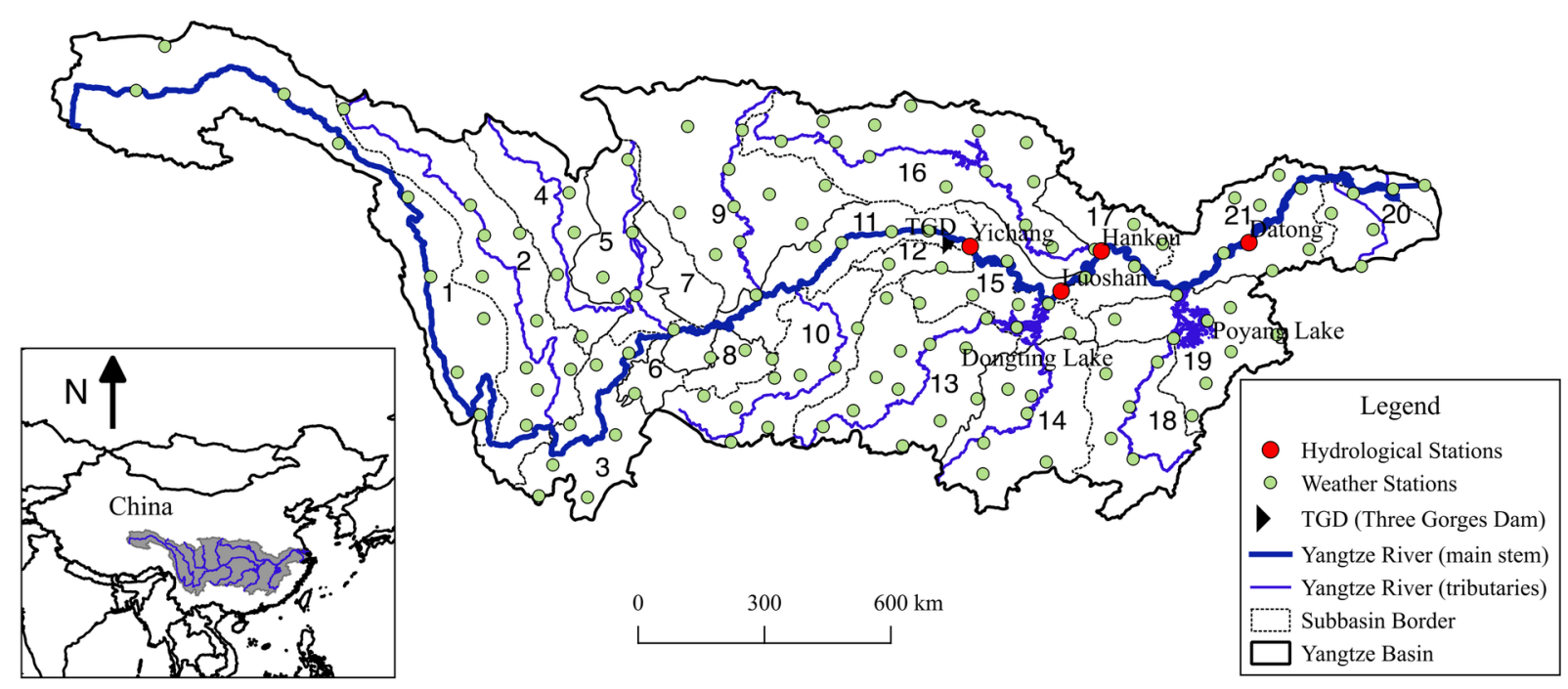

HYP_13619_Figure 1_final.tif

This article is protected by copyright. All rights reserved. 

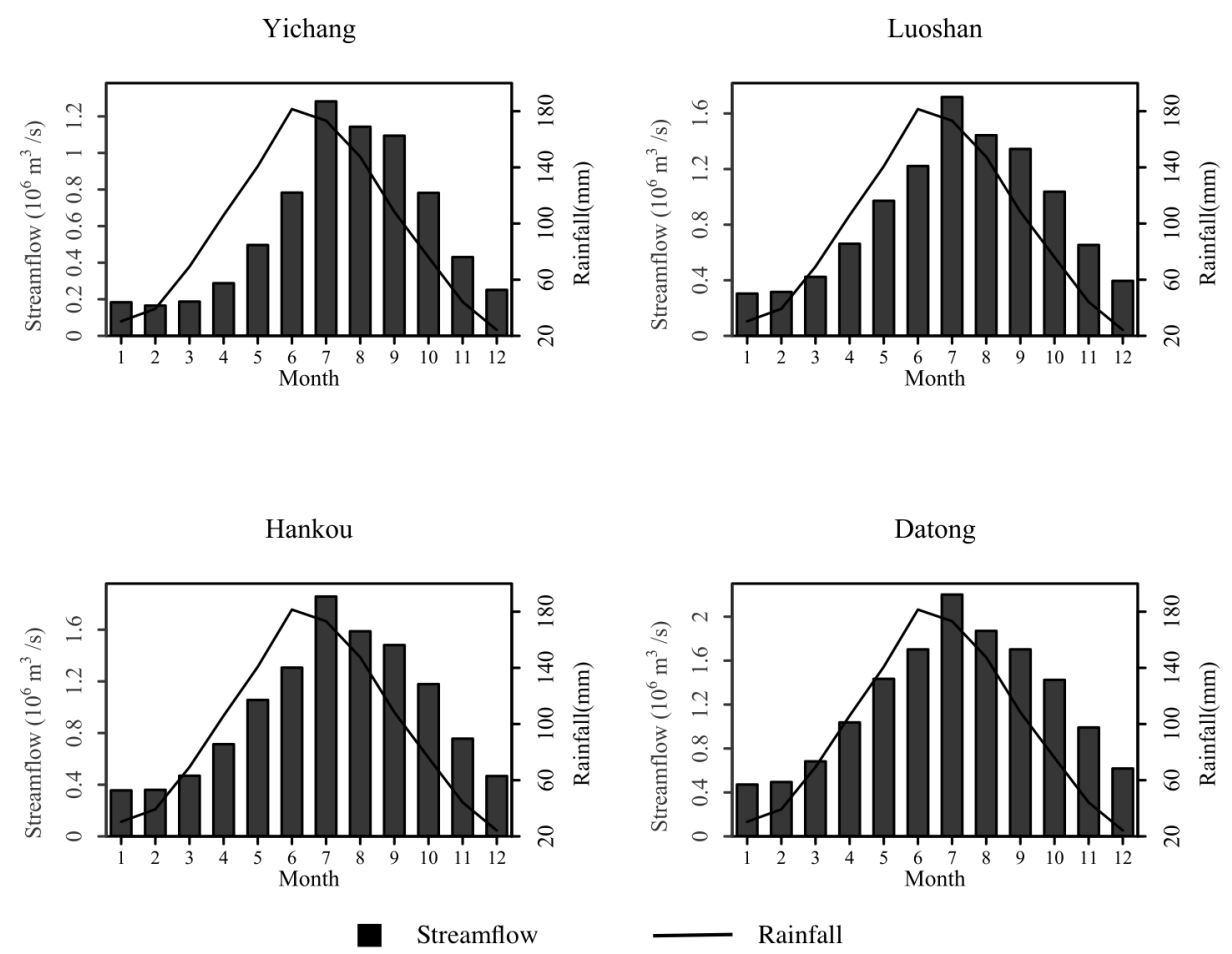

HYP_13619_Figure 2_final.tif

This article is protected by copyright. All rights reserved. 

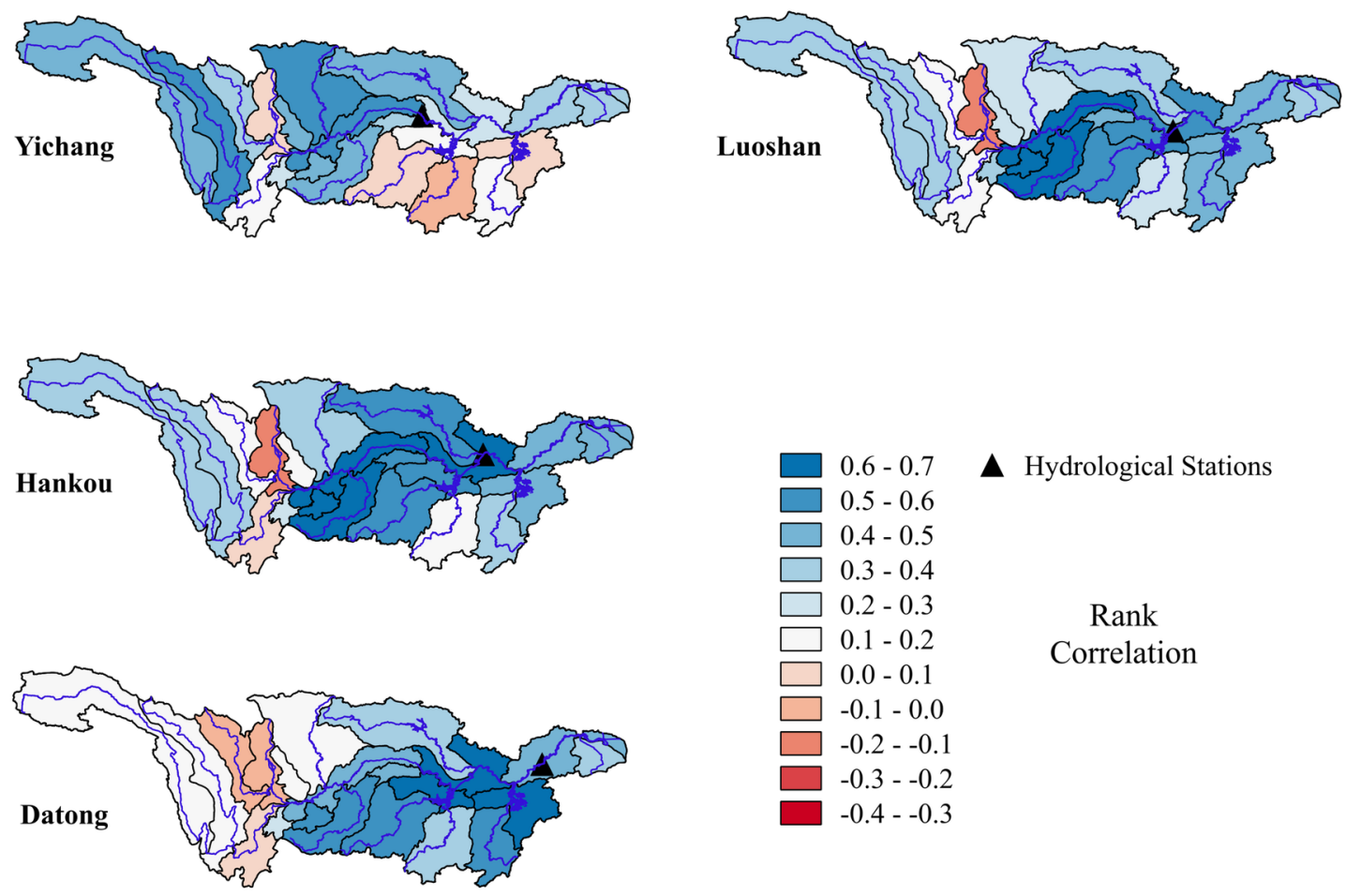

Correlation

HYP_13619_Figure 3_final.tif

This article is protected by copyright. All rights reserved. 

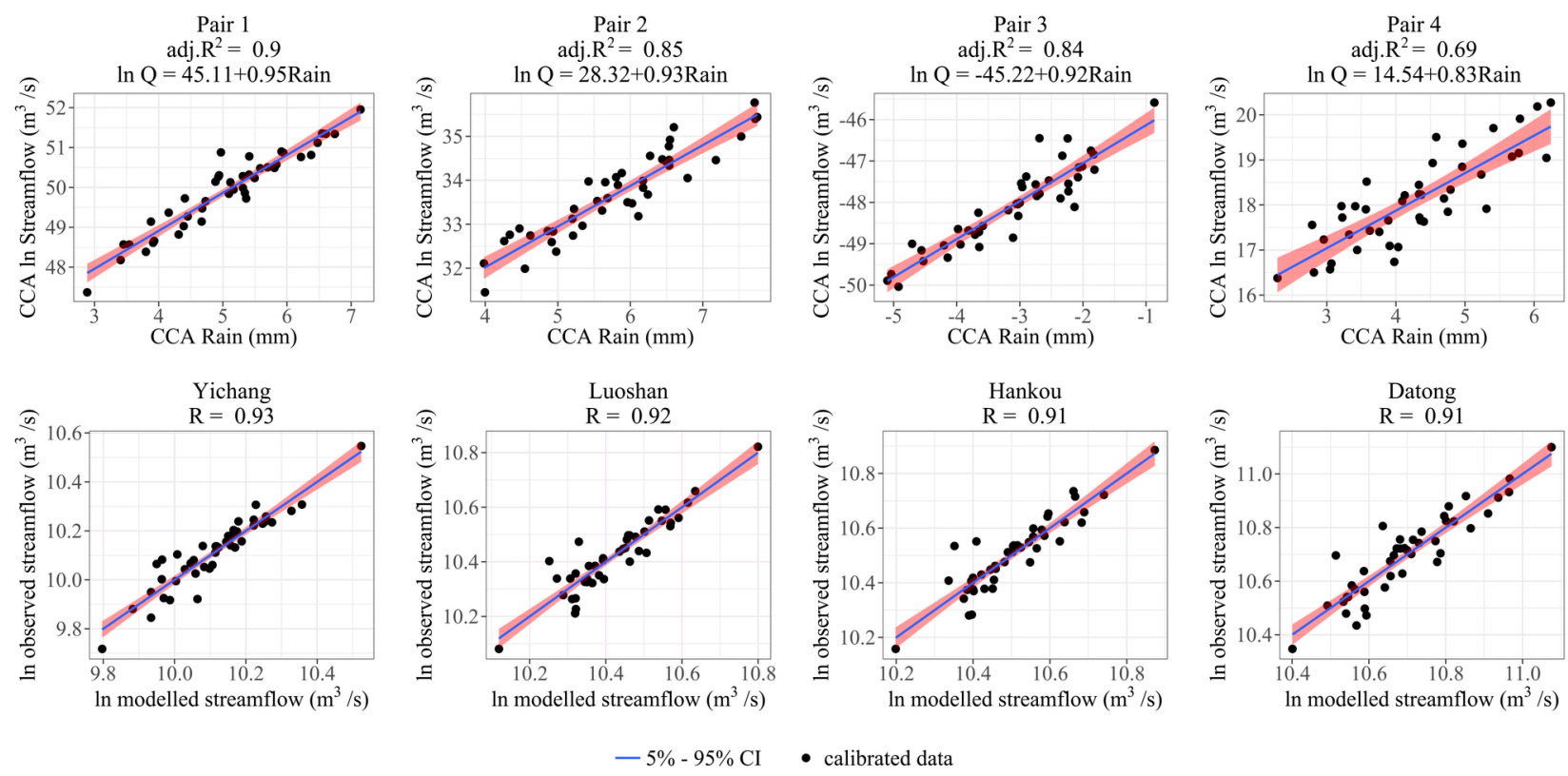

$-5 \%-95 \% \mathrm{CI} \cdot$ calibrated data

HYP_13619_Figure 4_final.tif 

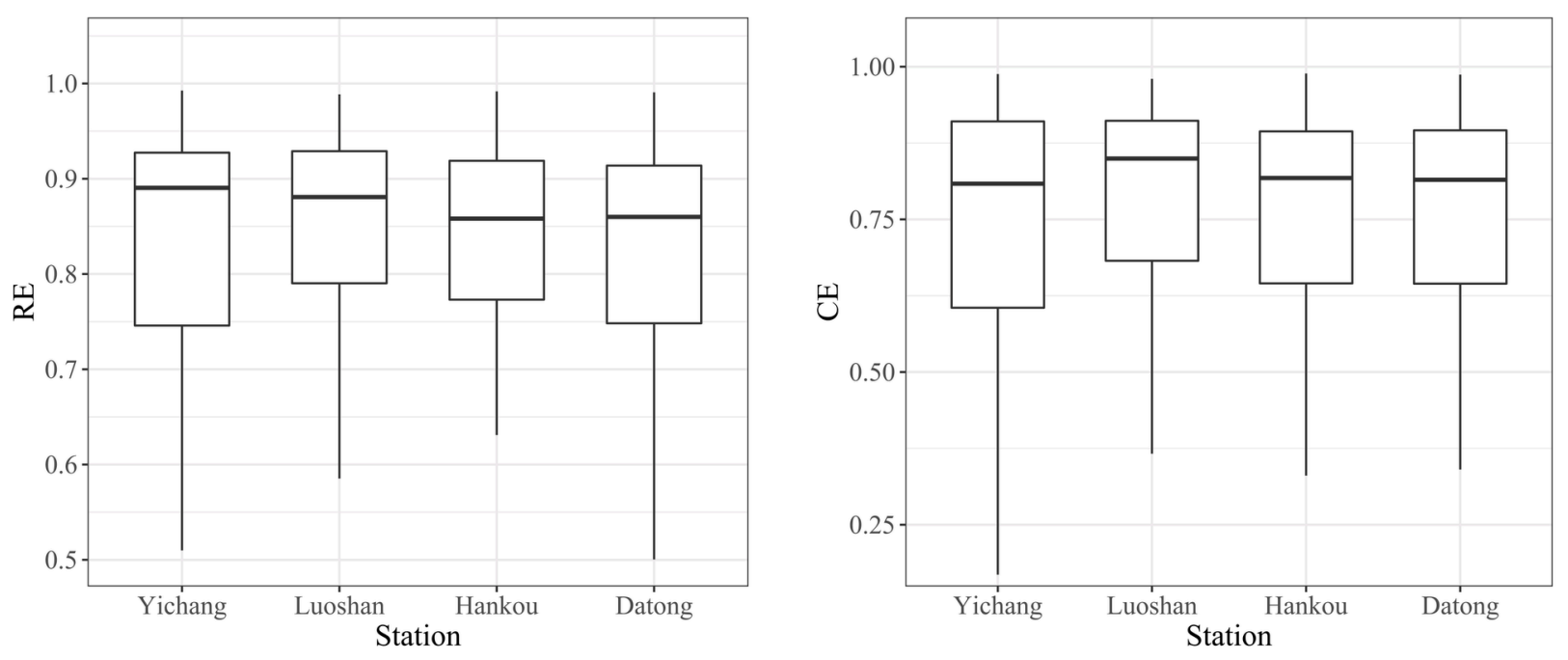

HYP_13619_Figure 5_final.tif

This article is protected by copyright. All rights reserved. 


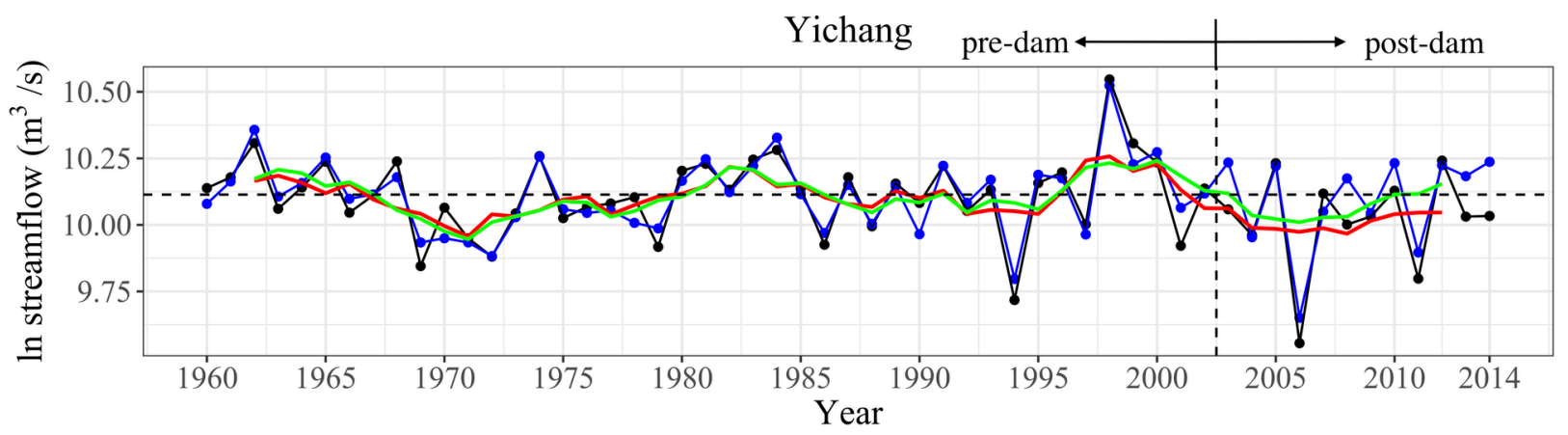

Luoshan

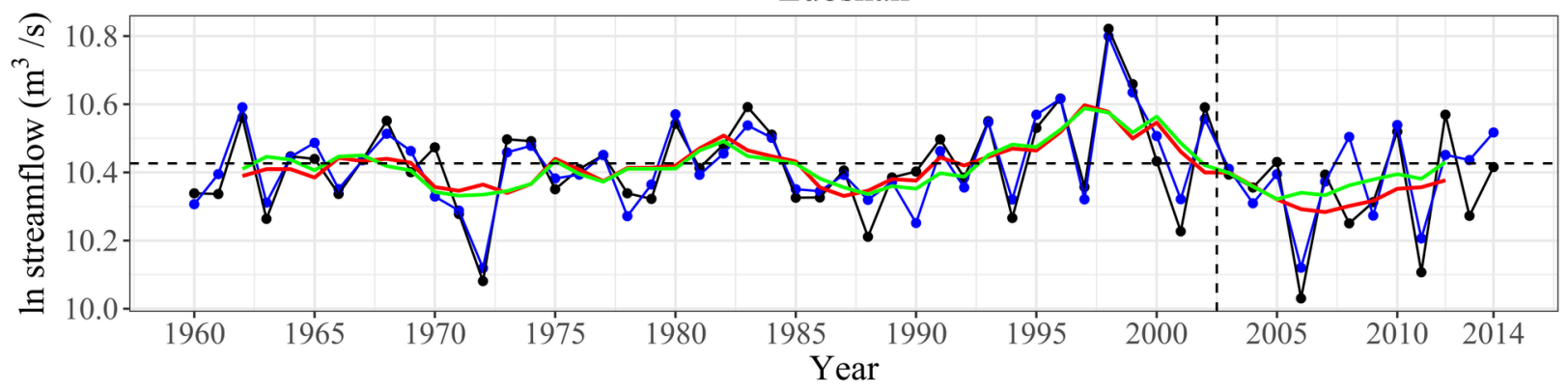

Hankou

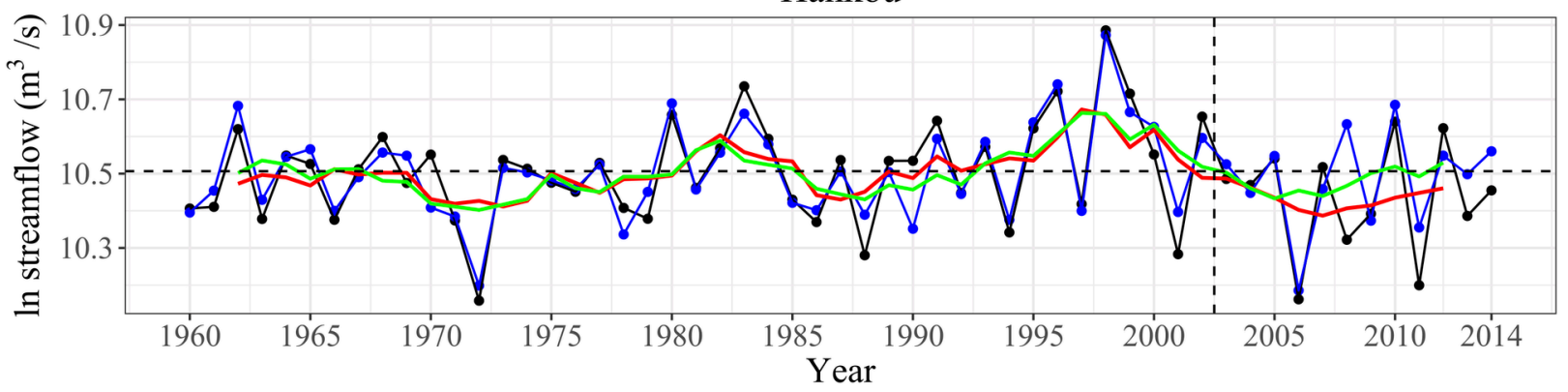

Datong

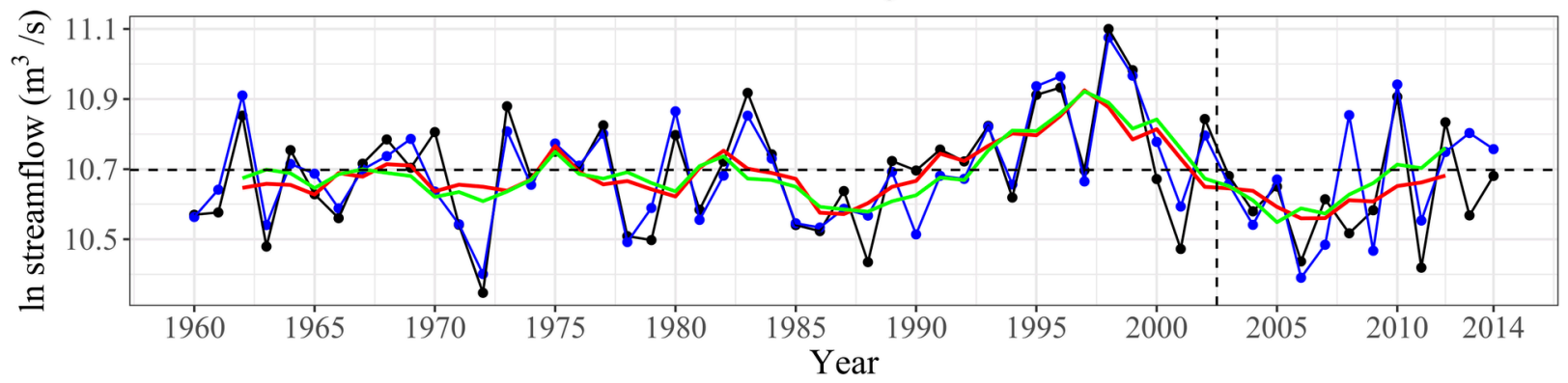

- 5yr mov.ave.for modelled data $\quad-5$ yr mov.ave.for observed data $\rightarrow$ modelled data $\rightarrow$ observed data

HYP_13619_Figure 6_final.tif

This article is protected by copyright. All rights reserved. 

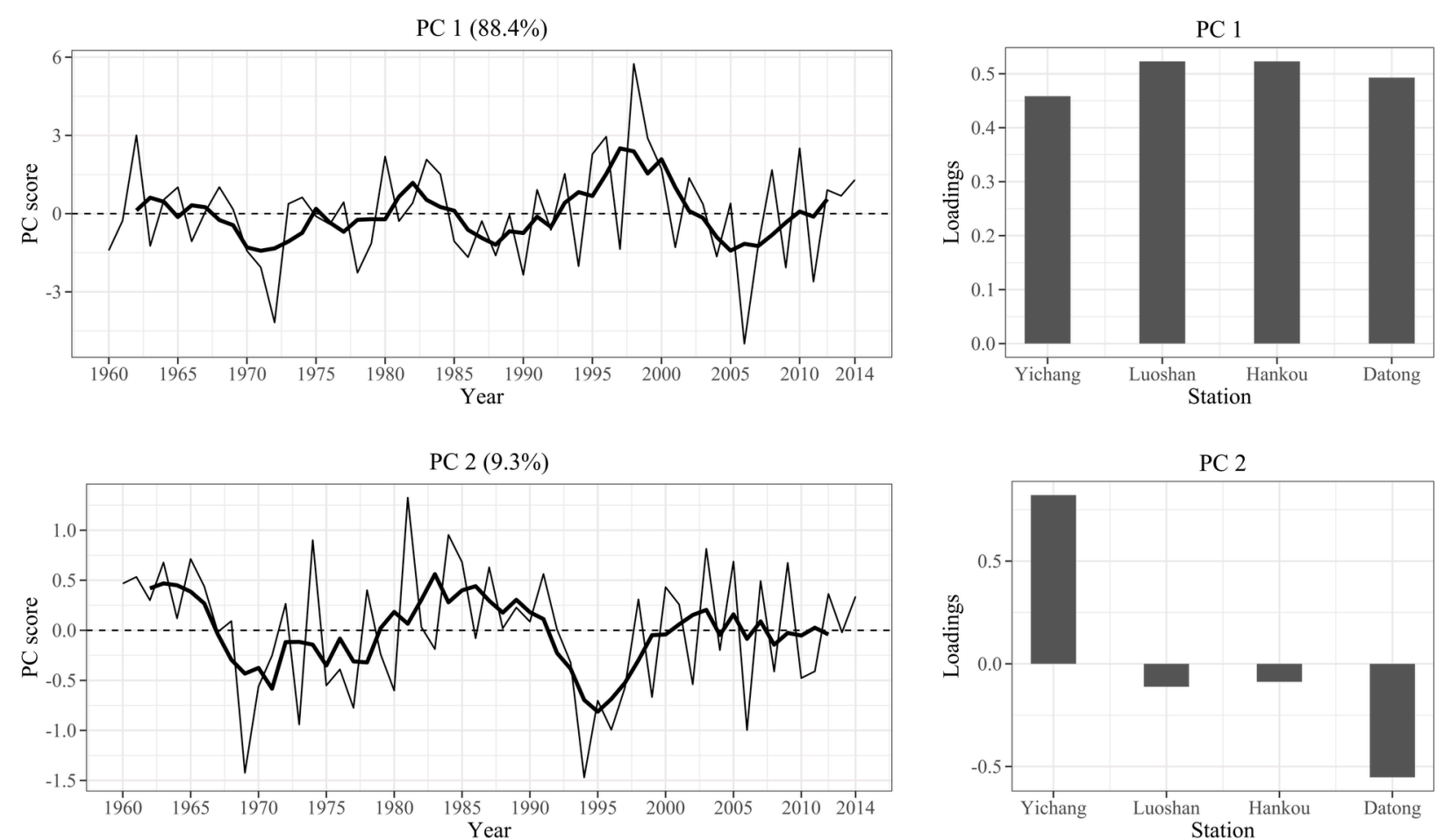

- 5yr mov.ave. $\longrightarrow$ PC - - - - PC score $=0$

HYP_13619_Figure 7_final.tif

This article is protected by copyright. All rights reserved. 


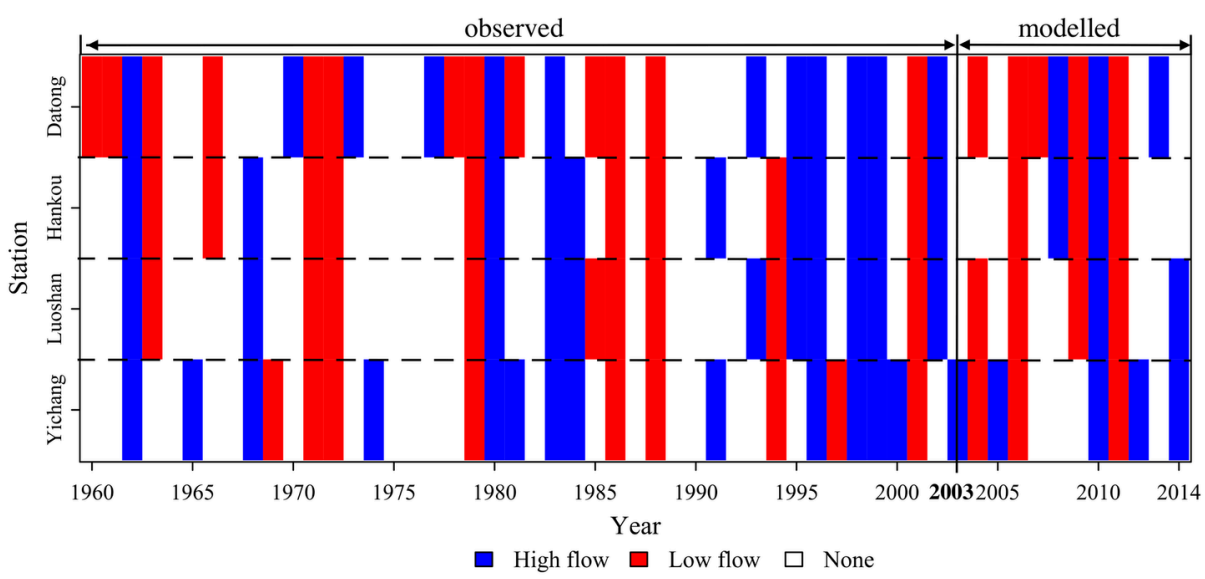

HYP_13619_Figure 8_final.tif

This article is protected by copyright. All rights reserved. 

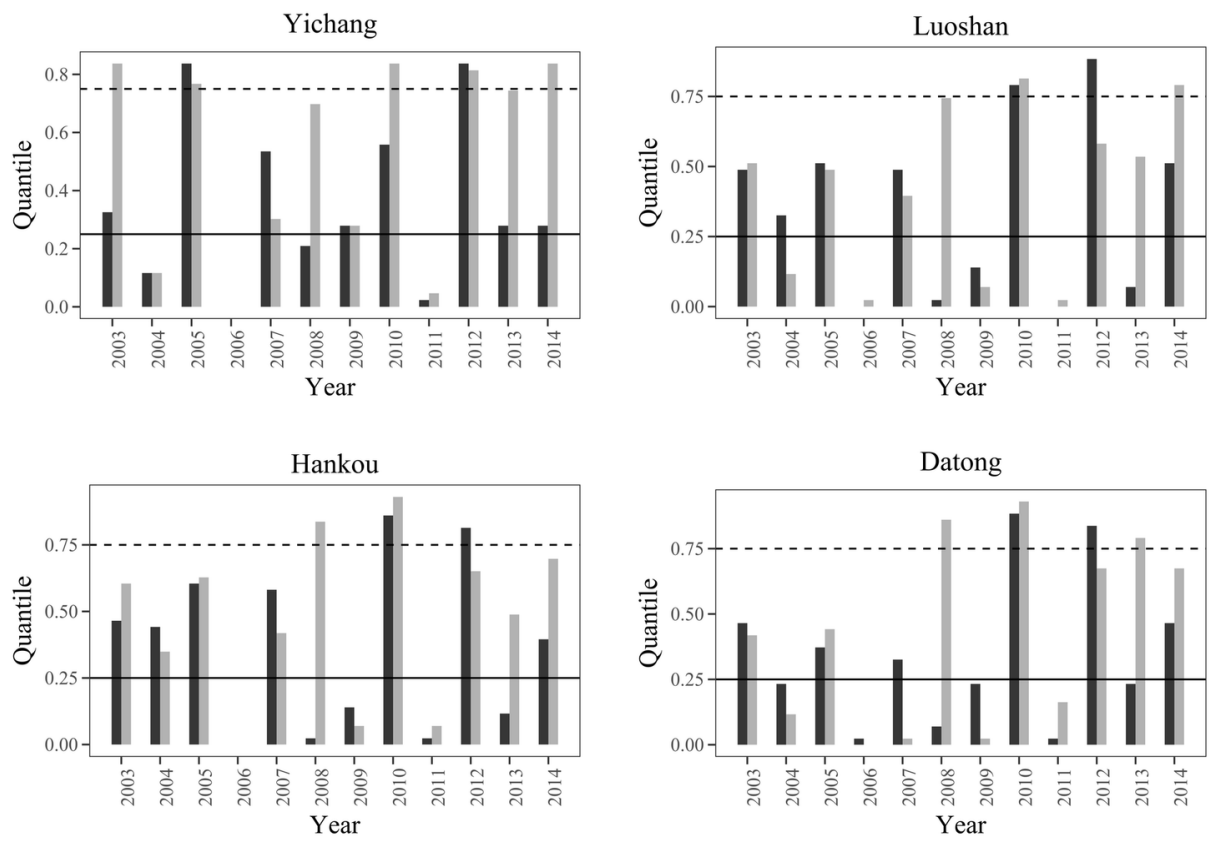

- - - High flow — Low flow

Observation Modelled naturalized flows

HYP_13619_Figure 9_final.tif

This article is protected by copyright. All rights reserved. 


\section{University Library}

\section{- M M N E R VA A gateway to Melbourne's research publications}

Minerva Access is the Institutional Repository of The University of Melbourne

Author/s:

Su, Z;Ho, M;Hao, Z;Lall, U;Sun, X;Chen, X;Yan, L

Title:

The impact of the Three Gorges Dam on summer streamflow in the Yangtze River Basin

Date:

2019-11-25

Citation:

Su, Z., Ho, M., Hao, Z., Lall, U., Sun, X., Chen, X. \& Yan, L. (2019). The impact of the Three Gorges Dam on summer streamflow in the Yangtze River Basin. HYDROLOGICAL PROCESSES, 34 (3), pp.705-717. https://doi.org/10.1002/hyp.13619.

Persistent Link:

http://hdl.handle.net/11343/286661 